\title{
TU/e EmonONEN

\section{A robust and general approach to quantitatively conjugate enzymes to plasmonic nanoparticles}

Citation for published version (APA):

Wang, Y., van Asdonk, K., \& Zijlstra, P. (2019). A robust and general approach to quantitatively conjugate enzymes to plasmonic nanoparticles. Langmuir, 35(41), 13356-13363.

https://doi.org/10.1021/acs.langmuir.9b01879

\section{Document license:}

CC BY-NC-ND

DOI:

10.1021/acs.langmuir.9b01879

Document status and date:

Published: 23/09/2019

\section{Document Version:}

Publisher's PDF, also known as Version of Record (includes final page, issue and volume numbers)

\section{Please check the document version of this publication:}

- A submitted manuscript is the version of the article upon submission and before peer-review. There can be important differences between the submitted version and the official published version of record. People interested in the research are advised to contact the author for the final version of the publication, or visit the $\mathrm{DOI}$ to the publisher's website.

- The final author version and the galley proof are versions of the publication after peer review.

- The final published version features the final layout of the paper including the volume, issue and page numbers.

Link to publication

\section{General rights}

Copyright and moral rights for the publications made accessible in the public portal are retained by the authors and/or other copyright owners and it is a condition of accessing publications that users recognise and abide by the legal requirements associated with these rights.

- Users may download and print one copy of any publication from the public portal for the purpose of private study or research.

- You may not further distribute the material or use it for any profit-making activity or commercial gain

- You may freely distribute the URL identifying the publication in the public portal.

If the publication is distributed under the terms of Article 25fa of the Dutch Copyright Act, indicated by the "Taverne" license above, please follow below link for the End User Agreement:

www.tue.nl/taverne

Take down policy

If you believe that this document breaches copyright please contact us at:

openaccess@tue.nl

providing details and we will investigate your claim. 


\title{
A Robust and General Approach to Quantitatively Conjugate Enzymes to Plasmonic Nanoparticles
}

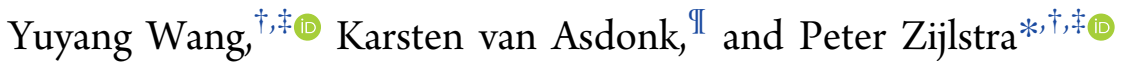 \\ ${ }^{\dagger}$ Department of Applied Physics, Eindhoven University of Technology, 5600 MB, Eindhoven, The Netherlands \\ ${ }^{\ddagger}$ Institute for Complex Molecular Systems, 5600 MB, Eindhoven, The Netherlands \\ IIDepartment of Biomedical Engineering, Eindhoven University of Technology, 5600 MB, Eindhoven, The Netherlands
}

\author{
Supporting Information
}

\begin{abstract}
Bioconjugates of plasmonic nanoparticles have received considerable attention due to their potential biomedical applications. Successful bioconjugation requires control over the number and activity of the conjugated proteins and the colloidal stability of the particles. In practice, this requires reoptimization of the conjugation protocol for each combination of protein and nanoparticle. Here, we report a robust and general protocol that allows for the conjugation of

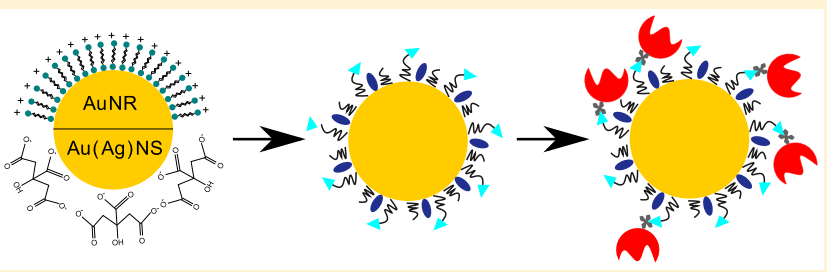
a range of proteins to different types of nanoparticles using very short polyethylene-glycol(PEG) linkers, while simultaneously preserving protein activity and colloidal stability. The use of short linkers ensures that the protein is located close to the particle surface, where the refractive index sensitivity and near-field enhancement are maximal. We demonstrate that the use of a Tween 20 containing stabilizing buffer is critical in maintaining colloidal stability and protein function throughout the protocol. We obtain quantitative control over the average number of enzymes per particle by either varying the number of functional groups on the particle or the enzyme concentration during incubation. This new route of preparing quantitative proteinnanoparticle bioconjugates paves the way to develop rational and quantitative strategies to functionalize nanoparticles for applications in sensing, medical diagnostics, and drug delivery.
\end{abstract}

\section{INTRODUCTION}

Plasmonic noble metal nanoparticles are suitable for a large variety of scientific and commercial applications, such as sensing, spectroscopy, and energy conversion, due to their outstanding optical properties. ${ }^{1-4}$ These optical properties are governed by the unique localized surface plasmon resonance (LSPR), which are essentially coherently oscillating electrons in the conduction band induced by radiation with an electromagnetic wave. The optical properties of plasmonic particles are easily fine-tuned by changing their size, shape, and material via various well-developed wet chemistry protocols, leading to a rich library of available plasmonic nanoparticles directly for research. ${ }^{5-7}$ One of the most important consequences of LSPRs is the localized electromagnetic field around the nanoparticles, which causes plasmon resonance peak shifts in response to local refractive index changes. ${ }^{8}$ Plasmonic particles can also act as antennas to modify the photophysical properties of single fluorescent molecules by modulation of the excitation rate, radiative, and nonradiative decay rate. ${ }^{9-12}$ Plasmonic particles are therefore ideal candidates for enhanced molecular detection and are indispensable tools in single-molecule imaging and biosensing. ${ }^{4}$

Bioconjugates of plasmonic particles have therefore received considerable attention, for example, particles functionalized with proteins, peptides, or oligonucleotides are increasingly found as important players in biosensors, ${ }^{13-17}$ nanocarriers, $^{18,19}$ and nanotherapeutics. ${ }^{20-23}$ Nevertheless, complex molecular interactions exist at the interface between the nanoparticle and the conjugated biomolecules. The colloidal stability of the nanoparticles, the hydrodynamic behavior of the suspending medium, and the folded structure of the biomolecules all play pivotal roles in successful bioconjugation. ${ }^{24}$ Several challenges are associated with the controlled preparation of nanoparticle bioconjugates, especially via a robust and general protocol. To begin with, there is a large diversity of surface ligands including surfactants and polymers that keep the as-synthesized nanoparticles colloidally stable. In practice, this requires a tailored ligand exchange protocol to keep each type of particle stable during the conjugation. Second, quantitative determination of the number of biomolecules per nanoparticle is inherently difficult because reaction stoichiometry often does not directly relate to the added molar ratio of nanoparticle and biomolecule. Third, the inherent dispersion in nanoparticle size and ligand density could complicate the control over colloidal stability and biomolecular display on nanoparticles.

Various strategies to conjugate biomolecules to colloidal nanoparticles have been proposed. ${ }^{25}$ Biomolecules can be directly adsorbed onto the nanoparticle's surface by physisorption. However, physisorption often leads to (local)

Received: June 20, 2019

Revised: August 20, 2019

Published: September 23, 2019 
unfolding of the biomolecules resulting in significant loss of bioactivity. ${ }^{26-29}$ Bioconjugation via a ligand or a polymeric linker is widely used to avoid direct contact of the biomolecules with the nanoparticle surface. Standard bioconjugation techniques have been introduced using bifunctional cross-linkers. Electrostatic adsorption via linkers with charged end groups has been shown to effectively conjugate proteins to gold nanoparticles. ${ }^{30,31}$ Multibranched polymers and dendrimers have also been used for bioconjugation via various surface chemistries and have been particularly useful to functionalize particles for drug delivery and applications in undiluted complex media. ${ }^{32,33}$ The most widely used covalent approach uses $\mathrm{N}$-(3-dimethylaminopropyl)- $\mathrm{N}$-ethylcarbodiimide hydrochloride (EDC) and its derived cross-linkers connecting primary amines on the biomolecule with carboxyls on the particle via amide bonds. ${ }^{25}$ Both gold and silver nanoparticles have been conjugated to proteins and peptides using such EDC-mediated protocols. ${ }^{34-36}$ However, the required strict control of $\mathrm{pH}$ and ionic strength leaves only a narrow window in which the particles remain colloidally stable, and this window varies from colloid to colloid depending on the charge and type of capping ligand. Bio-orthogonal approaches using click chemistry have shown to allow accurate quantitation of the average number of biomolecules per particle. ${ }^{37-39}$ However, click reactions rely on hydrophobic azide or alkyne groups on either the particle or on the biomolecule, which often leads to reduced solubility and colloidal stability in aqueous environments. ${ }^{40}$ Conjugation via biotin-streptavidin linkers has been used in the study of nanoparticle-based biosensors on ensemble and singlemolecule levels and the study of nanoparticle assemblies. $^{13,41-44}$ Being a water-soluble small molecule, biotin is typically conjugated to the surface of nanoparticles via poly(ethylene)-glycol(PEG) cross-linkers, without significant aggregation of the nanoparticles. ${ }^{25,45}$ However, maintaining colloidal stability requires long PEG linkers to prevent aggregation during centrifugation or at physiological salt conditions, pushing the conjugated biomolecules away from the particle's surface where the refractive index sensitivity and fluorescence enhancements are highest. ${ }^{15,46}$ Although it has been observed that histidine-tagged biomolecules can effectively conjugate to inorganic quantum dots with zerolength spacing, ${ }^{47}$ no general protocols exist that allow for the conjugation of a range of proteins to different types of plasmonic nanoparticles using short linkers while simultaneously preserving protein activity and colloidal stability.

In this manuscript, we demonstrate a general and robust approach to quantitatively conjugate a range of enzymes to a range of metal nanoparticles using short linkers. Owing to the different stabilizing ligands employed during the synthesis of the particles, we demonstrate that the use of a Tween 20 containing stabilizing buffer is critical in maintaining colloidal stability and protein function throughout the functionalization process. To show the generality of the approach, we conjugate alkaline phosphatase (ALP), $\beta$-galactosidase ( $\beta$-gal), and horseradish peroxidase (HRP) to as-synthesized gold nanospheres, gold nanorods, and silver nanospheres that each display different surface ligands and different $\zeta$-potentials. We obtain quantitative control over the average number of enzymes per particle by changing either the number of functional groups on the particle or by changing the enzyme concentration during incubation. Quantitative conjugation of proteins to nanoparticles will enable the use of these bioconjugates in nanomedicine, cellular targeting, and biosensing. Although displayed with diluted buffers, our method is not limited by real undiluted samples, such as serum and whole blood, due to the high conjugation specificity and detection sensitivity.

\section{EXPERIMENTAL SECTION}

Nanoparticle PEGylation. Gold and silver nanospheres $(40 \mathrm{~nm}$ in diameter) stabilized in sodium citrate buffer were purchased from Sigma-Aldrich. Gold nanorods $\left(60 \times 30 \mathrm{~nm}^{2}\right.$, extinction peak 610 $\mathrm{nm})$ were purchased from Nanoseedz. The gold and silver nanospheres were directly used for PEGylation, whereas gold nanorods were centrifuged once and resuspended in an aqueous solution containing $1 \mathrm{mM}$ CTAB. SH-PEG-biotin ( $1 \mathrm{kDa})$ was purchased from Nanocs and SH-PEG-methyl $(800 \mathrm{Da})$ was purchased from Sigma-Aldrich. Stock solutions of PEG were aliquoted at $2 \mathrm{mM}$ in $\mathrm{MQ}$ water and stored frozen at $-20{ }^{\circ} \mathrm{C}$. The mixed solutions of PEG with varying fractions $\left(\chi_{b}\right)$ of SH-PEG-biotin were then prepared in $10 \mathrm{mM}$ Tris(2-carboxyethyl)phosphine hydrochloride (TCEP) solution in MQ water to prevent formation of disulfide bridges.

For PEGylation, $100 \mu \mathrm{L}$ of nanoparticle solution was centrifuged in to a pellet (9000 rpm, $10 \mathrm{~min})$, and a $100 \mu \mathrm{L}$ solution of the mixed PEG-solution at $1 \mathrm{mM}$ total concentration was added to the pellet, vortexed, and incubated for at least $4 \mathrm{~h}$. After PEGylation, the PEGylated nanoparticles were centrifuged and redispersed at least $5 \times$ in a Tris or PBS buffer with $0.1 \%$ of Tween 20 added to it. The addition of Tween 20 was crucial as it ensured colloidal stability throughout the protocol with no significant aggregation (visible as a red-shift and/or broadening of the extinction spectrum) and prevents loss of particles due to sticking to the walls of the eppendorf tube.

Enzyme Conjugation. Streptavidin-conjugated enzyme ( $\beta$ galactosidase, alkaline phosphatase, and horseradish peroxidase) were obtained from Sigma-Aldrich. Stock solutions of enzyme were prepared in buffer. The buffer used for ALP was $25 \mathrm{mM}$ Tris with 0.1 wt $\%$ Tween 20 at $\mathrm{pH} 9$, and the buffer for $\beta$-gal and HRP was $10 \mathrm{mM}$ phosphate buffered saline with 0.1 wt $\%$ Tween 20 at $\mathrm{pH}$ 7.4. For enzyme conjugation, stock solutions of the enzyme were added to PEGylated nanoparticle solutions to a final concentration of enzyme ranging from 1-100 nM. The nanoparticle-enzyme mixture was vortexed for $10 \mathrm{~s}$ and kept at $-4{ }^{\circ} \mathrm{C}$ for at least $12 \mathrm{~h}$ before being centrifuged and redispersed at least $5 \times$ in the same Tween 20 containing buffer. This ensured that nearly no free enzyme was left in the solution (see Figure S1 in the Supporting Information). Despite different ionic strength and $\mathrm{pH}$ of the buffers, we found that the use of Tween20 was again crucial to ensure colloidal stability.

Quantification of Conjugate Stoichiometry. The prepared bioconjugate was then ready for the determination of the final nanoparticle and enzyme concentration, the ratio of which provides the stoichiometric number of enzymes per particle. The former was determined by UV-vis extinction spectroscopy for which the extinction spectra of the nanoparticle suspensions were measured in a Shimadzu 2600 spectrophotometer in a quartz cuvette with an optical path length of $l=3 \mathrm{~mm}$. The nanoparticle concentration was then determined by the Lambert-Beer law $c_{\mathrm{NP}}=\frac{A}{\epsilon_{\text {exc }}}$, where $\mathrm{A}$ is the measured extinction value and $\epsilon_{e x c}$ is the molar extinction coefficient.

To determine the concentration of enzymes, the fluorogenic enzyme substrate 7-hydroxy-9H-(1,3-dichloro-9,9-dimethylacridin-2one) (DDAO) was used for ALP and $\beta$-gal. DDAO phosphate and DDAO galactose were used as substrates for ALP and $\beta$-gal, respectively, and Amplex Red was used for HRP in the presence of hydrogen peroxidase. All enzyme substrates were purchased from Thermofisher. For DDAO-based enzyme reactions, the enzymes cleave the phoshate or galactose groups, leading to the recovery of DDAO fluorescence, whereas Amplex Red reacts with hydrogen peroxidase in the presence of HRP, producing highly fluorescent resorufin. Stock solutions of the substrates were prepared in dimethyl sulfoxide (DMSO) and stored at $-20{ }^{\circ} \mathrm{C}$ before dissolving in Tris or 
a) I

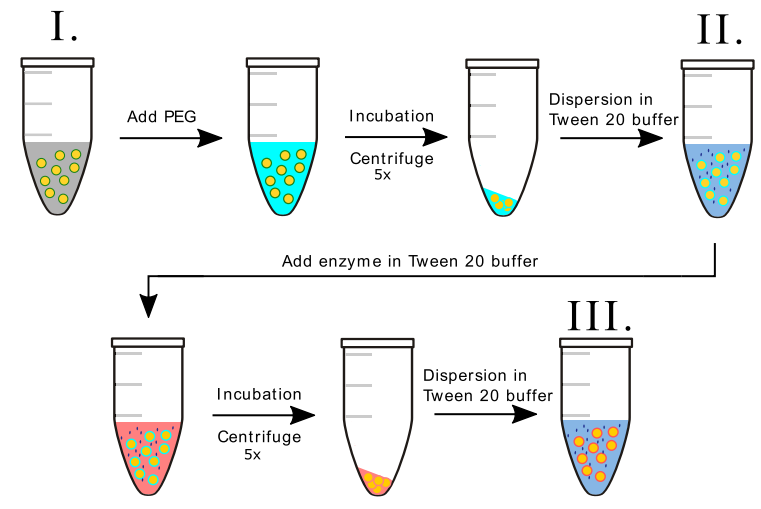

b)

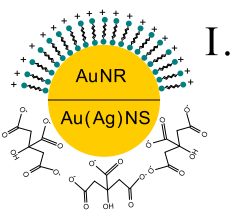

c)<smiles>CCOCCCS</smiles>

SH-PEG-methyl, MW $=800 \mathrm{Da}$

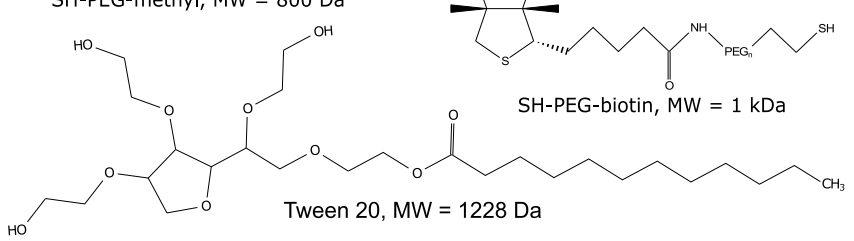

Figure 1. (a) Workflow of the bioconjugation. Prior to the protocol, plasmonic nanoparticles (yellow) are stabilized by their native ligands (green) in an ionic buffer (gray). After centrifugation, the pellet from the native solution is incubated with a mixed PEG solution (cyan) for PEGylation After PEGylation, the mixture is purified by centrifugation $(5 \times)$ followed by redispersion in Tween 20 containing buffer (blue), indicated as state II. Enzyme stock solutions (red) prepared in Tween 20 containing buffer are then added to the mixture, followed again by incubation and purification by centrifugation $(4 \times)$. The nanoparticle-enzyme bioconjugates are finally dispersed in Tween 20 containing buffer, indicated by state III. (b) Sketches of the nanoparticle surface chemistry in states I, II, and III as shown in part a. In state I, the nanoparticles are stabilized by either the positively charged surfactant CTAB (AuNR) or by negatively charged citrate ions (AuNS and AgNS). In state II, the nanoparticles are stabilized by a mixed PEG layer (black) with exposed biotin groups (cyan) and Tween20 (dark blue). In state III, the enzyme is conjugated via biotinstreptavidin linkage. (c) Molecular structure of the thiolated PEG linkers and Tween20 used in the bioconjugation. The spherical shape of the nanoparticles is only for illustration and does not attempt to describe the true geometry.

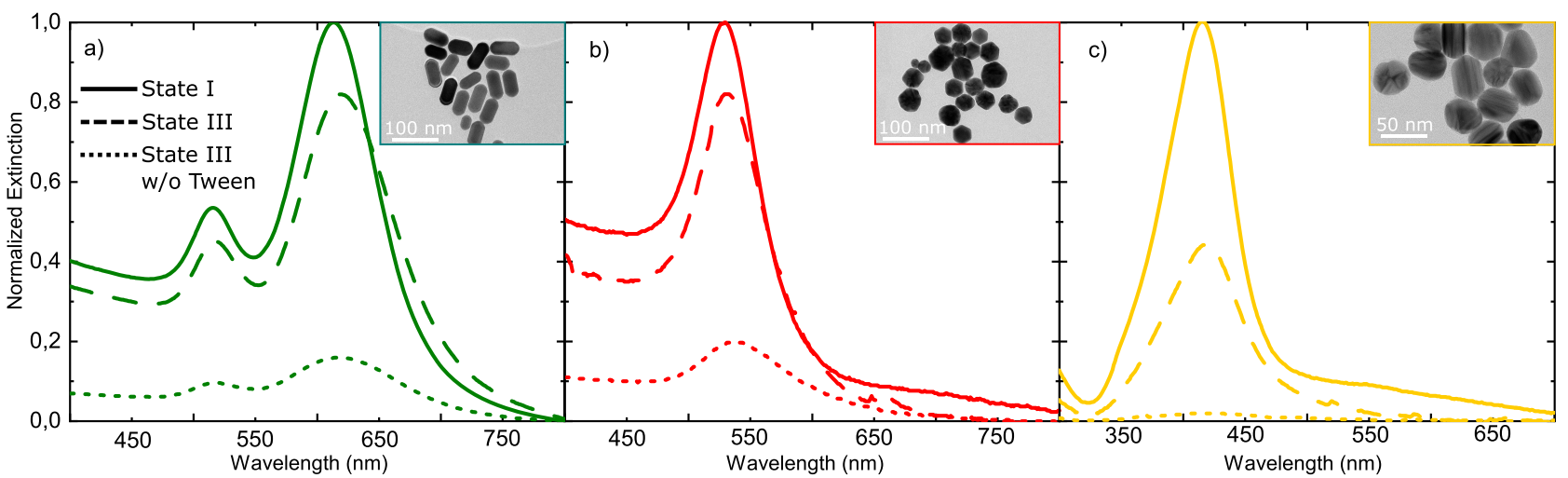

Figure 2. UV-vis extinction spectra of (a) AuNR, (b) AuNS, and (c) AgNS before and after enzyme conjugation in states I (solid line) and III (dashed line). For comparison, we also show the spectra in state III where no Tween 20 was used in the whole protocol. In the insets, we show the transmission electron microscope (TEM) images of the corresponding nanoparticles used in the conjugation.

PBS buffer for enzymatic assays. A Fluoroskan Ascent FL well plate reader (Thermofisher) was used to read out the fluorogenic enzymatic reactions from 96-well plates. In an enzymatic assay, a total volume of $100 \mu \mathrm{L}$ of solution was pipetted in to each well and mixed, after which the fluorescence signal was recorded as a function of time. An excitation/emission filter pair of $647 / 660 \mathrm{~nm}$ was used for DDAObased reactions, and 560/580 nm was used for Amplex Red reactions.

\section{RESULTS AND DISCUSSION}

In Figure 1a, we show the workflow of the bioconjugation in which the nanospheres and nanorods with different native surface charges are used for conjugation with streptavidinconjugated enzymes. Colloidal synthesis of plasmonic metal nanoparticles relies on the reduction of metal ions in aqueous solution, and the most widely used plasmonic nanoparticles prepared are gold and silver nanospheres and gold nanorods. For the synthesis of gold and silver nanospheres (AuNS, AgNS), citric acid is usually used as a reducing agent and as a stabilizer, preventing the aggregation of nanoparticles by a high density of negative charges on the surface. ${ }^{48,49}$ For the synthesis of gold nanorods (AuNR), high concentrations $(>10 \mathrm{mM}$ ) of the surfactant CTAB have to be present acting as a shape regulator, guiding the growth of spherical seeds into elongated nanoparticles. As a result, the synthesized AuNRs are coated with a dense bilayer of positively charged CTAB molecules providing colloidal stability.

It is ideal to fully remove the citrate or $\mathrm{CTAB}$ in the nanoparticle solution, since biological applications of nanoparticles cannot be pursued with either citrate or $\mathrm{CTAB}$ at high concentration due to their cytotoxity. ${ }^{50,51}$ A simple removal usually will cause aggregation because the surface charge that provides electrostatic stabilization is diminished. SH-PEGs and their derivatives are therefore often used to remove most of the surfactant and act as a steric stabilizer for the particles. ${ }^{5,45,52}$ PEGylation of nanoparticles has been widely reported in literature, $5,7,45,52$ and from these studies, it is known that colloidal stability in high ionic strength solutions is only achieved with PEG linkers $>5 \mathrm{kDa}$. To facilitate bioconjugation via shorter PEG linkers $<1 \mathrm{kDa}$, we adapted the PEGylation protocol by Liao et al. ${ }^{45}$ and used a solution of mixed SH-PEG- 
Table 1. Extinction Coefficients of the Nanoparticles at the Wavelengths at Which Exctintion Peaks and $\zeta$-Potentials of Nanoparticles and Nanoparticle-ALP Bioconjugates in the Three States are Displayed in Figure 1

\begin{tabular}{|c|c|c|c|c|c|}
\hline Nanoparticle (dimensions) & $\epsilon_{e x c}\left(\mathrm{M}^{-1} \mathrm{~cm}^{-1}\right)$ & $\mathrm{c}_{N P}(\mathrm{nM})$ & $\zeta(\mathrm{mV})$ state I & $\zeta(\mathrm{mV})$ state II & $\zeta(\mathrm{mV})$ state III \\
\hline $\operatorname{AuNR}\left(60 \times 30 \mathrm{~nm}^{2}\right)$ & $2.5 \times 10^{9}$ & $0.8 \pm 0.05$ & $26.2 \pm 0.757$ & $-14.9 \pm 1.04$ & $-22.6 \pm 1.67$ \\
\hline AuNS $(40 \mathrm{~nm})$ & $8.4 \times 10^{9}$ & $0.12 \pm 0.01$ & $-37.8 \pm 0.75$ & $-15.3 \pm 0.551$ & $-23.8 \pm 0.513$ \\
\hline $\operatorname{AgNS}(40 \mathrm{~nm})$ & $3.7 \times 10^{10}$ & $0.066 \pm 0.005$ & $-39.1 \pm 1.05$ & $-15.3 \pm 1.97$ & $-22.0 \pm 0.723$ \\
\hline
\end{tabular}
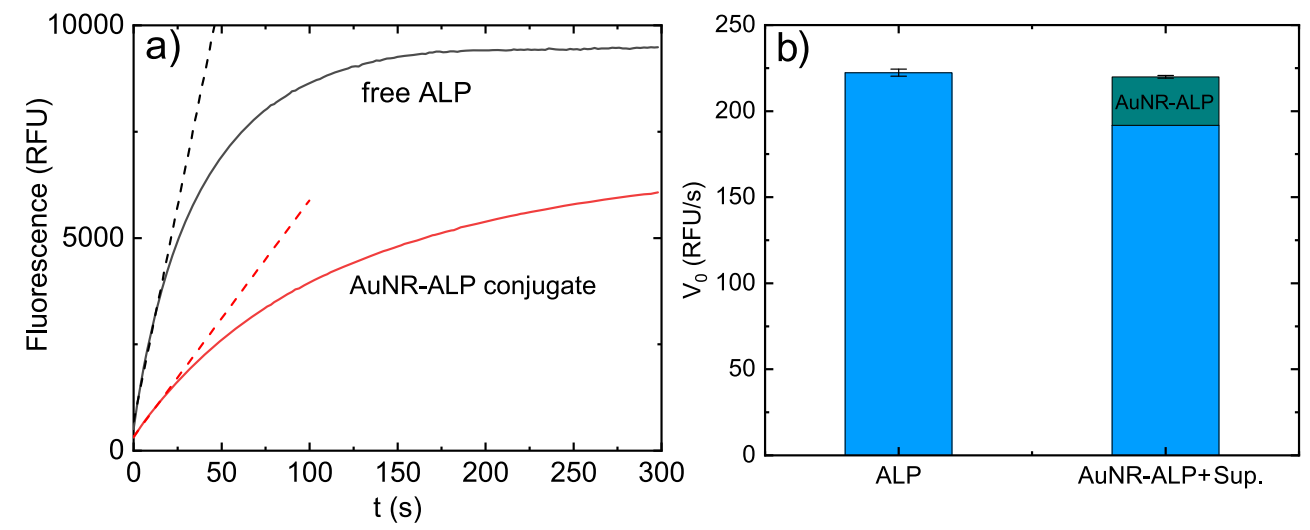

Figure 3. (a) Progress curves of $1 \mathrm{nM}$ free streptavidin-ALP and a AuNR-ALP bioconjugate prepared with $50 \mathrm{nM}$ ALP during conjugation. The corresponding fits to the initial phase of the progress curves yield the initial velocity $V_{0}$. (b) Initial velocities of $5 \mathrm{nM}$ free ALP (blue, left), AuNRALP bioconjugate (green), and the supernatant (blue, right).

biotin and SH-PEG-methyl in the presence of Tween20 to PEGylate and simultaneously biotinylate the surface of nanoparticles with a controlled fraction of biotin groups (Figure 1b). The use of a mixed PEG layer enables us to vary the number of biotin groups per particle while keeping the total PEG coverage constant. This allows us to directly compare the different functionalization protocols.

The use of short PEG linkers decreases the absolute distance between the molecule and nanoparticle surface, maximizing the refractive index sensitivity and fluorescence enhancements. In the ideal chain model, ${ }^{53}$ the end-to-end distance of a polymer chain scales as $\sqrt{ } N$, with $N$ as the number of segements in the chain. Reducing the PEG length from $5 \mathrm{kDa}$ to $1 \mathrm{kDa}$ therefore reduces the time-averaged spacing between the biomolecule and the particle by $\sim 2 \mathrm{~nm}$, which is substantial considering the short length of the localized electric field around these small particles. As an example, the $1 /$ e decay length of field intensity is about $5 \mathrm{~nm}$ for a gold nanorod with a diameter of $30 \mathrm{~nm}$. ${ }^{46}$

The colloidal stability of the suspensions can be conveniently monitored using UV-vis spectroscopy, as aggregation of the particles will result in a red-shift of the plasmon resonance and eventually a loss of extinction. In Figure 2, we show the UV-vis spectra of the nanoparticles before and after bioconjugation with streptavidin-ALP in Tween 20 containing Tris buffer at $\mathrm{pH} 9$, and also the spectra of the bioconjugate prepared without Tween 20 in the buffer throughout the whole protocol. We observed that for all nanoparticles, no obvious aggregation was found as there was no large shift $(<10 \mathrm{~nm})$ in extinction peaks, and no major loss of nanoparticles was found when Tween 20 was present throughout the bioconjugation (see Figure S2 in the Supporting Information). In contrast, the $\mathrm{UV}$-vis spectra of bioconjugates prepared without Tween 20 stabilization showed a $4-10 \times$ decrease in final extinction values. This is caused by the formation of large aggregates of particles that cannot be redispersed. Tween 20 prevents this aggregation by stabilizing the nanoparticles' surface by transiently absorbing to areas of low PEG density. This indicates that Tween 20 played a crucial role in boosting the colloidal stability of the nanoparticles. The minor decrease of peak extinction when Tween20 was present during the conjugation compared to stock solution was largely from pipetting losses during the centrifugation cycles. The bigger loss in extinction for AgNS could be due to partial surface oxidation, reducing their stability.

The $\zeta$-potentials of the nanoparticles in states I, II, and III were also measured to understand the surface modification of PEGylation and bioconjugation as shown in Table 1. As can be seen, the $\zeta$-potentials of nanoparticles in their native solutions vary due to different surface ligands, and after PEGylation, all particles showed $\zeta$-potentials of about $-15 \mathrm{mV}$, indicating the successful and reproducible modification of the nanoparticle surfaces regardless of their native surface charges. Note here that the $\zeta$-potential of PEG coated nanoparticles was reported by others to be PEG-length dependent, and $\zeta$-potentials closer to zero could be found for PEGylated nanoparticles with longer PEGs $(>5 \mathrm{kDa}) .{ }^{54}$ After the bioconjugation with ALP, the $\zeta$-potential of all nanoparticles showed a decrease to about $-23 \mathrm{mV}$, indicating the successful binding of the negatively charged streptavidin-enzyme complex. The $\zeta$-potential of $\beta$ gal-nanoparticle bioconjugates was found to be of similar magnitude.

After the bioconjugation, the enzyme concentration was determined using the fluorogenic substrates DDAOp, DDAOg, and Amplex Red. Note here that fluorogenic enzymatic reactions were specifically used for quantitative determination rather than optical absorption or extinction to prevent interference from the extinction caused by the nanoparticles and other biomolecules in solution. Now the only interference could be from other fluorescent species, which are absent in our solutions (the quantum yield of gold nanoparticles is $\left.<10^{-5}\right) .{ }^{55}$ The enzymatic reactions were visualized as progress curves of fluorescence intensity as a function of time. The enzyme concentration was then determined from the initial velocity $V$ (that is, the initial rate of fluorescence increase) by 

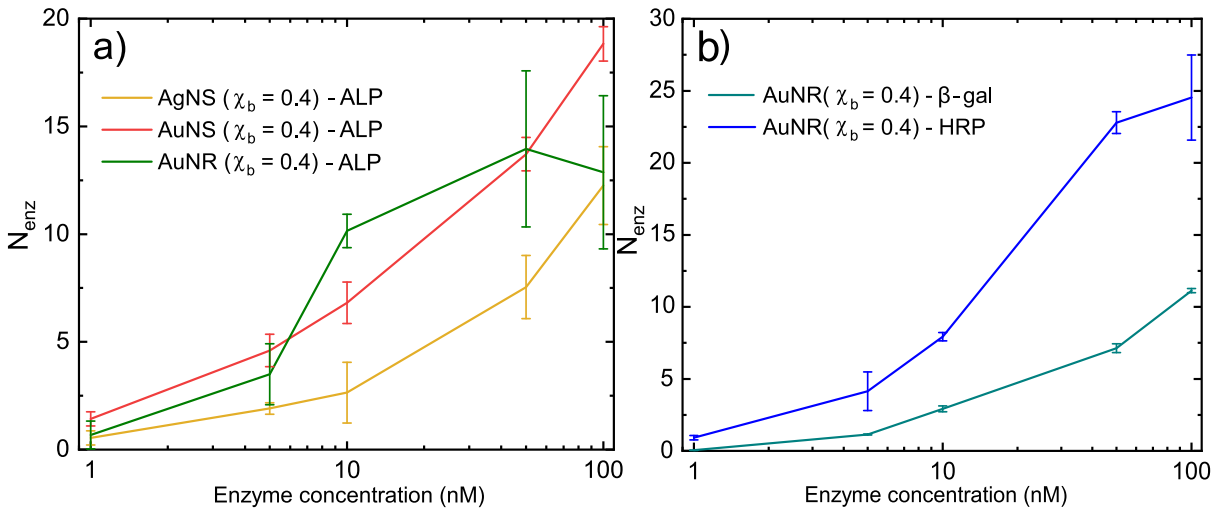

Figure 4. (a) Number of ALP par particle as a function of ALP concentration for AuNR, AuNS, and AgNS bioconjugates. (b) Number of $\beta$-gal per particle as a function of $\beta$-gal concentration for AuNR bioconjugates. $\chi_{b}=0.4$ is fixed during bioconjugation.

assuming Michaelis-Menten kinetics (see Figure S3 in the Supporting Information). As an example, we demonstrate the determination of the number ALPs per gold nanorod in Figure 3. The average number of ALPs per gold nanorod $N_{e n z}$ is given the by the fraction of the concentration of active enzymes $c_{e n z}$ and the concentration of nanoparticles in the bioconjugate $c_{N P}$

$$
N_{e n z}=\frac{c_{e n z}}{c_{N P}}
$$

The effective concentration of conjugated enzyme, $c_{\text {enz }}$ was determined from the ratio between the initial velocity of the bioconjugate and the free enzyme at a known concentration, given by

$$
c_{e n z}=\frac{V_{0}^{\text {conj }}}{V_{0}^{\text {free }}}
$$

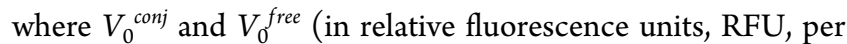
second) are the initial velocity of the bioconjugate and the free enzyme solution with a known concentration. In Figure 3a, we show the progress curves of $1 \mathrm{nM}$ free streptavidin-conjugated ALP and the AuNR-ALP bioconjugate. The initial-phase of the progress curve is fitted with a linear equation in the form of $V$ $=a+V_{0} t$, with the slope $V_{0}$ as the initial velocity. Significant nonlinearity of the progress curves sets in after $20 \mathrm{~s}$ due to substrate depletion. In this particular case, we find $c_{e n z}=10$ $\mathrm{nM}$, which resulted in $N_{\text {enz }}=12$ based on the nanoparticle concentration of $0.78 \mathrm{nM}$.

One question that remains to be addressed is whether the nanoparticle-conjugated enzymes are as active when conjugated to the nanoparticles as in their free state. More often than not enzymes conjugated to nanoparticles show significantly decreased activity due to conformational changes during, e.g., physisorption or covalent enzyme modifications that are unfavorable to maintain activity. In contrast, in some circumstances, an increased enzyme activity upon immobilization has been reported. ${ }^{56}$ The mechanism behind the nanoparticle-induced enhancement is complex as it involves the enzyme's conformation, accessibility of the active site, and the local chemical environment (charge, $\mathrm{pH}$ ) near the particle that may promote or inhibit activity. Nevertheless, it has been confirmed that the unique microenvironment surrounding the nanoparticles and the enzyme's physicochemical interaction with the particle may modify the enzyme's catalytic activity.

To assess the enzyme's activity before and after conjuation, we performed a supernatant assay of the AuNR bioconjugates prepared with $50 \mathrm{nM}$ ALP. In Figure $3 \mathrm{~b}$, we show the initial velocities of $5 \mathrm{nM}$ free streptavidin-ALP and the sum of the activities of the bioconjugate after centrifugation and the supernatant. We observe that the enzyme activity of the bioconjugate was nearly $100 \%$ of the original activity. We attribute the high retention of activity to the dense PEG layer on the particle and on the noncovalent biotin-streptavidin interactions due to which very little to no modifications of protein structure are expected during the bioconjugation.

We now demonstrate that the number of enzymes per particle can be quantitatively controlled for different enzymes and particles by (1) controlling the enzyme concentration during incubation or (2) controlling the fraction of biotin groups in the mixed PEG layer. To demonstrate the effect of enzyme concentration used during the bioconjugation on $N_{\text {enz }}$, we measured $N_{e n z}$ for bioconjugates prepared with a concentration series of ALP and $\beta$-gal. In Figure 4, we show the measured $N_{e n z}$ determined for AuNR, AgNS, and AuNS coated with a mixed layer of PEG with a biotin fraction $\chi_{b}=$ 0.4. As we can see in Figure $4 \mathrm{a}, N_{\text {enz }}$ for nanoparticle-ALP bioconjugates can be controlled by the ALP concentration giving access to stoichiometries ranging from monovalent up to 20 enzymes per particle when the enzyme concentration was increased from 1 to $100 \mathrm{nM}$. Note that $N_{\text {enz }}$ is a measurement of active enzymes only and may not represent the true coverage of enzyme molecules since inactive enzymes do not contribute to the initial velocity, meaning that we are 'blind' in our measurement to the enzymes that are inactive already in the stock solutions. Nevertheless, the maximum value of $N_{e n z}$ is limited by number of biotin groups and by the physical size of the enzyme compared to the particle. Despite their surface area, the number of enzymes on the AuNRs reached a plateau at the highest enzyme concentrations, whereas the coverage on the nanospheres was not saturated yet. We hypothesize that this might be due to the less efficient removal of CTAB from the AuNR surface leading to a lower number of biotin groups per particle.

The generality of the protocol is demonstrated in Figure $4 b$, where we show $N_{e n z}$ for AuNR- $\beta$-gal and AuNR-HRP bioconjugates. We found that $N_{\text {enz }}$ for $\beta$-gal and HRP also scaled with enzyme concentration during incubation and reached approximately $N_{e n z}{ }^{\max }=10$ and 25, respectively, at 100 $\mathrm{nM}$ incubation. The lower $\mathrm{N}_{e n z}{ }^{\max }$ for AuNR- $\beta$-gal compared to ALP and HRP is likely due to the bigger physical size of $\beta$ gal $(520 \mathrm{kDa})$ compared to those of ALP $(140 \mathrm{kDa})$ and HRP $(44 \mathrm{kDa})$, leading to a larger footprint of the protein. 
The theoretical maximum number of enzymes per particle $N_{e n z}{ }^{\max }$ for ALP and $\beta$-gal can be estimated by assuming that the particles exhibit a perfectly spherical or spherically capped cylindrical geometry. These particle shapes exhibit a surface area $A_{N P}$ that for spherical particles can be written as $A_{N P}{ }^{s p h}=$ $4 \pi r^{2}$ with $r$ as the particle radius. For a spherically capped cylinder, the surface area available for enzyme conjugation is given by $A_{N P}{ }^{r o d}=4 \pi r^{2}+2 \pi r(L-2 r)$, where $r$ is the radius of the rod and $L$ is its length. The maximum number of enzymes then follows from

$$
N_{e n z}{ }^{\max }=f \frac{A_{N P}}{A_{e n z}}
$$

where $A_{N P}$ is the surface area of the respective particle shape, $A_{\text {enz }}$ is the estimated footprint of a single enzyme molecule, and $f=0.4$ is a correction factor to account for the fact that random sequential absorption leads to a maximum surface coverage of approximately $40 \% .^{57,58}$ The random sequential absorption describes a process where enzymes are introduced randomly, and irreversibly adsorb on a surface. It is commonly used to estimate the maximum coverage of spherical objects such as proteins on a surface. The footprint $A_{\text {enz }}$ of single enzymes without streptavidin was estimated using data from the protein databank, giving $A_{e n z}=252 \mathrm{~nm}^{2}$ for $520 \mathrm{kDa} \beta$-gal, $A_{\text {enz }}=60$ $\mathrm{nm}^{2}$ for $140 \mathrm{kDa} \mathrm{ALP}$, and $A_{\text {enz }}=31 \mathrm{~nm}^{2}$ for $44 \mathrm{kDa}$ HRP. In Table 2, we show $N_{e n z}^{\max }$ based on these estimates. Our

Table 2. Estimated Maximum Number of Enzymes Per Particle $N_{e n z}^{\text {max }}$

\begin{tabular}{ccccc} 
Nanoparticle & $A_{N P}\left(\mathrm{~nm}^{2}\right)$ & $N_{A L P}^{\max }$ & $N_{\beta \text {-gal }}^{\max }$ & $N_{H R P}^{\text {max }}$ \\
AuNR $\left(60 \times 30 \mathrm{nM}^{2}\right)$ & $5650 \mathrm{~nm}^{2}$ & 37 & 9 & 73 \\
AuNS, AgNS $(40 \mathrm{nM})$ & $5030 \mathrm{~nm}^{2}$ & 34 & 8 & 65 \\
\hline
\end{tabular}

experimental $\mathrm{N}_{e n z}^{\text {max }}$ of up to 20,11, and 24 for ALP, $\beta$-gal, and HRP, respectively, are thus reasonable numbers and indicate that the found maximum coverage is limited by the available surface area for random sequential absorption of the enzymes. Small deviations from the estimated maximum number could be due to the actual density of biotin on the nanoparticle surface, the presence of streptavidin, the size-dispersion of the particles, and electrostatic-repulsion between neighboring enzymes leading to a lower coverage than expected from the random sequential absorption model.

Finally, we demonstrate that the biotin fraction $\chi_{b}$ can also be used to tune $N_{e n z}$. We prepared PEGylated AuNRs with $\chi_{b}$ ranging from 0.001 up to 0.4 and used $10 \mathrm{nM}$ ALP for bioconjugation. As shown in Figure 5, $N_{e n z}$ increases from 1 to 9 with increasing $\chi_{b}$. This indicates that by increasing the number of biotins on the nanoparticle surface, the capture of the enzyme from the solution becomes more efficient leading to a larger number of enzymes per particle. The result also shows that SH-PEG-methyl $(800 \mathrm{Da})$ provides excellent antifouling because at low biotin fractions, we find a strongly reduced number of enzymes per particle, indicating little to no nonspecific binding of streptavidin-conjugated enzymes to $\mathrm{SH}$ PEG-methyl.

As an outlook of our approach, we envision the resolution of the number and position of the conjugated enzymes by using microscopy methods. Transmission or scanning electron microscopes, for example, can be employed to perform this task after immunolabeling the enzymes with very small $(<5$ $\mathrm{nm}$ ) metallic nanoparticles. The number and distribution of

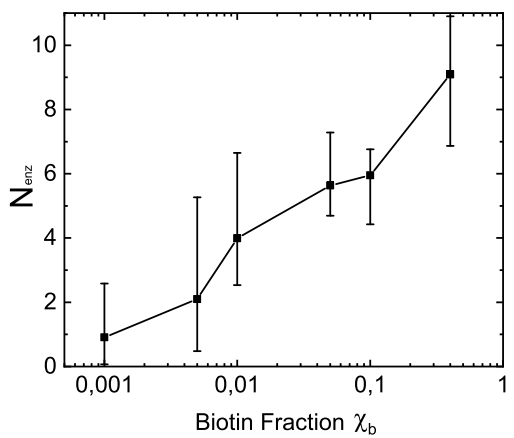

Figure 5. Number of ALP as a function of biotin fraction $\chi_{b}$ at fixed ALP concentration of $10 \mathrm{nM}$ during conjugation.

enzymes can then be visualized with the help of the high electron density of the labeling nanoparticles. ${ }^{59}$ Stochastic super-resolution microscopy based on sequentially blinking fluorophores can also be used as a powerful tool to localize single molecules on a single-particle basis and has been successfully performed on gold nanoparticles with high spatial resolution. ${ }^{19,60,61}$

Understanding the number and distribution of enzymes on single particles is important in a number of applications. For example, it has been found that the density of enzymes on the nanoparticle surface directly impacts the enzyme activity, which needs to be taken into account when using enzymatic conversions for label-free analyte detection. ${ }^{62}$ Enzyme quantity and distribution were also established to be crucial in the performance of enzyme-powered nanomotors, where a certain threshold of enzyme numbers and asymmetric distribution was needed to generate nanoparticle motion. ${ }^{18,19}$

\section{CONCLUSION}

We have developed a general approach to quantitatively conjugate enzymes to plasmonic nanoparticles including AuNRs, AuNS, and AgNS. The nanoparticles were first PEGylated with a mixture of SH-PEG-biotin and SH-PEGmethyl and then effectively stabilized in an enzyme reaction buffer containing Tween20. Then the PEGylated nanoparticles were conjugated to streptavidin-conjugated enzymes in the same buffer. We showed that our approach minimized particle aggregation and facilitated quantification of the number of enzymes per nanoparticle using fluorogenic enzyme assays, and we demonstrated that the bound enzymes maintained their biological activity. We could control the number of specifically bound enzymes per particle by varying the enzyme concentration and biotin fraction on the nanoparticle surface. Our protocol features high robustness and generality, due to the use of Tween 20 as a stabilizing agent, and is highly versatile and flexible due to the use of commercially available mixed layers of PEG. This new route of quantitative proteinnanoparticle bioconjugate preparation that we demonstrated here may assist in the development of rational strategies to use nanoparticle bioconjugates in sensing, medical diagnostics, and other applications.

\section{ASSOCIATED CONTENT}

\section{S Supporting Information}

The Supporting Information is available free of charge on the ACS Publications website at DOI: 10.1021/acs.langmuir.9b01879. 
Supernatant assay, extinction spectra of bioconjugates, free enzyme kinetics (PDF)

\section{AUTHOR INFORMATION}

\section{Corresponding Author}

*E-mail: p.zijlstra@tue.nl.

\section{ORCID}

Yuyang Wang: 0000-0001-5175-8389

Peter Zijlstra: 0000-0001-9804-2265

Notes

The authors declare no competing financial interest.

\section{ACKNOWLEDGMENTS}

P.Z. and Y.W. acknowledge financial support from The Netherlands Organization for Scientific Research (NWO VIDI). Solliance and the Dutch province of Noord-Brabant are acknowledged for funding the TEM facility.

\section{REFERENCES}

(1) Zijlstra, P.; Orrit, M. Single metal nanoparticles: optical detection, spectroscopy and applications. Rep. Prog. Phys. 2011, 74, 106401.

(2) Csáki, A.; Thiele, M.; Jatschka, J.; Dathe, A.; Zopf, D.; Stranik, O.; Fritzsche, W. Plasmonic nanoparticle synthesis and bioconjugation for bioanalytical sensing. Engineering in Life Sciences 2015, 15, 266-275.

(3) Fabrizio, E. D.; Schlücker, S.; Wenger, J.; Regmi, R.; Rigneault, H.; Giuseppe, C.; West, M.; Cabrini, S.; Fleischer, M.; Hulst, N. F. v.; Garcia-Parajo, M. F.; Pucci, A.; Cojoc, D.; Hauser, C. A. E.; Ni, M. Roadmap on biosensing and photonics with advanced nano-optical methods. J. Opt. 2016, 18, 063003.

(4) Taylor, A. B.; Zijlstra, P. Single-Molecule Plasmon Sensing: Current Status and Future Prospects. ACS Sensors 2017, 2, 11031122.

(5) Murphy, C. J.; Thompson, L. B.; Alkilany, A. M.; Sisco, P. N.; Boulos, S. P.; Sivapalan, S. T.; Yang, J. A.; Chernak, D. J.; Huang, J. The Many Faces of Gold Nanorods. J. Phys. Chem. Lett. 2010, 1, 2867-2875.

(6) Lohse, S. E.; Murphy, C. J. The Quest for Shape Control: A History of Gold Nanorod Synthesis. Chem. Mater. 2013, 25, 12501261.

(7) Burrows, N. D.; Lin, W.; Hinman, J. G.; Dennison, J. M.; Vartanian, A. M.; Abadeer, N. S.; Grzincic, E. M.; Jacob, L. M.; Li, J.; Murphy, C. J. Surface Chemistry of Gold Nanorods. Langmuir 2016, 32, 9905-9921.

(8) Novotny, L.; Hecht, B. Principles of nano-optics; Cambridge University Press: 2012.

(9) Mertens, H.; Koenderink, A. F.; Polman, A. Plasmon-enhanced luminescence near noble-metal nanospheres: Comparison of exact theory and an improved Gersten and Nitzan model. Phys. Rev. B: Condens. Matter Mater. Phys. 2007, 76, 115123.

(10) Mertens, H.; Polman, A. Strong luminescence quantumefficiency enhancement near prolate metal nanoparticles: Dipolar versus higher-order modes. J. Appl. Phys. 2009, 105, 044302.

(11) Yuan, H.; Khatua, S.; Zijlstra, P.; Yorulmaz, M.; Orrit, M. Thousand-fold Enhancement of Single-Molecule Fluorescence Near a Single Gold Nanorod. Angew. Chem., Int. Ed. 2013, 52, 1217-1221.

(12) Khatua, S.; Paulo, P. M. R.; Yuan, H.; Gupta, A.; Zijlstra, P.; Orrit, M. Resonant Plasmonic Enhancement of Single-Molecule Fluorescence by Individual Gold Nanorods. ACS Nano 2014, 8, $4440-4449$.

(13) Beuwer, M. A.; Prins, M. W. J.; Zijlstra, P. Stochastic Protein Interactions Monitored by Hundreds of Single-Molecule Plasmonic Biosensors. Nano Lett. 2015, 15, 3507-3511.

(14) Messersmith, R. E.; Nusz, G. J.; Reed, S. M. Using the Localized Surface Plasmon Resonance of Gold Nanoparticles To
Monitor Lipid Membrane Assembly and Protein Binding. J. Phys. Chem. C 2013, 117, 26725-26733.

(15) Zijlstra, P.; Paulo, P. M. R.; Orrit, M. Optical detection of single non-absorbing molecules using the surface plasmon resonance of a gold nanorod. Nat. Nanotechnol. 2012, 7, 379-382.

(16) Wulf, V.; Knoch, F.; Speck, T.; Sönnichsen, C. Gold Nanorods as Plasmonic Sensors for Particle Diffusion. J. Phys. Chem. Lett. 2016, 7, 4951-4955.

(17) Paulo, P. M. R.; Zijlstra, P.; Orrit, M.; Garcia-Fernandez, E.; Pace, T. C. S.; Viana, A. S.; Costa, S. M. B. Tip-Specific Functionalization of Gold Nanorods for Plasmonic Biosensing: Effect of Linker Chain Length. Langmuir 2017, 33, 6503-6510.

(18) Patiño, T.; Arqué, X.; Mestre, R.; Palacios, L.; Sánchez, S. Fundamental Aspects of Enzyme-Powered Micro- and Nanoswimmers. Acc. Chem. Res. 2018, 51, 2662-2671.

(19) Patiño, T.; Feiner-Gracia, N.; Arqué, X.; Miguel-López, A.; Jannasch, A.; Stumpp, T.; Schäffer, E.; Albertazzi, L.; Sánchez, S. Influence of Enzyme Quantity and Distribution on the SelfPropulsion of Non-Janus Urease-Powered Micromotors. J. Am. Chem. Soc. 2018, 140, 7896-7903.

(20) Link, S.; El-Sayed, M. A. Shape and size dependence of radiative, non-radiative and photothermal properties of gold nanocrystals. Int. Rev. Phys. Chem. 2000, 19, 409-453.

(21) Wang, J.; Dong, B.; Chen, B.; Jiang, Z.; Song, H. Selective photothermal therapy for breast cancer with targeting peptide modified gold nanorods. Dalton Transactions 2012, 41, 11134-11144.

(22) Conde, J. a.; Dias, J. T.; Grazú, V.; Moros, M.; Baptista, P. V.; de la Fuente, J. M. Revisiting 30 years of biofunctionalization and surface chemistry of inorganic nanoparticles for nanomedicine. Front. Chem. 2014, 2, 48.

(23) Dreaden, E. C.; Alkilany, A. M.; Huang, X.; Murphy, C. J.; ElSayed, M. A. The golden age: gold nanoparticles for biomedicine. Chem. Soc. Rev. 2012, 41, 2740-2779.

(24) Nel, A. E.; Mädler, L.; Velegol, D.; Xia, T.; Hoek, E. M. V.; Somasundaran, P.; Klaessig, F.; Castranova, V.; Thompson, M. Understanding biophysicochemical interactions at the nanobiointerface. Nat. Mater. 2009, 8, 543-557.

(25) Hermanson, G. Bioconjugate Techniques; Elsevier: 2013.

(26) Dennison, J. M.; Zupancic, J. M.; Lin, W.; Dwyer, J. H.; Murphy, C. J. Protein Adsorption to Charged Gold Nanospheres as a Function of Protein Deformability. Langmuir 2017, 33, 7751-7761.

(27) Liu, F.; Wang, L.; Wang, H.; Yuan, L.; Li, J.; Brash, J. L.; Chen, H. Modulating the Activity of Protein Conjugated to Gold Nanoparticles by Site-Directed Orientation and Surface Density of Bound Protein. ACS Appl. Mater. Interfaces 2015, 7, 3717-3724.

(28) Shemetov, A. A.; Nabiev, I.; Sukhanova, A. Molecular Interaction of Proteins and Peptides with Nanoparticles. ACS Nano 2012, 6, 4585-4602.

(29) Keighron, J. D.; Keating, C. D. In NanoBiotechnology Protocols; Rosenthal, S. J., Wright, D. W., Eds.; Humana Press: Totowa, NJ, 2013; Vol. 1026; pp 163-174.

(30) Paulini, R.; Frankamp, B. L.; Rotello, V. M. Effects of Branched Ligands on the Structure and Stability of Monolayers on Gold Nanoparticles. Langmuir 2002, 18, 2368-2373.

(31) Hong, R.; Emrick, T.; Rotello, V. M. Monolayer-Controlled Substrate Selectivity Using Noncovalent Enzyme-Nanoparticle Conjugates. J. Am. Chem. Soc. 2004, 126, 13572-13573.

(32) Sahoo, S. K.; Labhasetwar, V. Nanotech approaches to drug delivery and imaging. Drug Discovery Today 2003, 8, 1112-1120.

(33) Kesharwani, P.; Jain, K.; Jain, N. K. Dendrimer as nanocarrier for drug delivery. Prog. Polym. Sci. 2014, 39, 268-307.

(34) Skewis, L. R.; Reinhard, B. M. Control of Colloid Surface Chemistry through Matrix Confinement: Facile Preparation of Stable Antibody Functionalized Silver Nanoparticles. ACS Appl. Mater. Interfaces 2010, 2, 35-40.

(35) Bartczak, D.; Kanaras, A. G. Preparation of Peptide-Functionalized Gold Nanoparticles Using One Pot EDC/Sulfo-NHS Coupling. Langmuir 2011, 27, 10119-10123. 
(36) Hinterwirth, H.; Lindner, W.; Lämmerhofer, M. Bioconjugation of trypsin onto gold nanoparticles: Effect of surface chemistry on bioactivity. Anal. Chim. Acta 2012, 733, 90-97.

(37) Brennan, J. L.; Hatzakis, N. S.; Tshikhudo, T. R.; Razumas, V.; Patkar, S.; Vind, J.; Svendsen, A.; Nolte, R. J. M.; Rowan, A. E.; Brust, M. Bionanoconjugation via Click Chemistry: The Creation of Functional Hybrids of Lipases and Gold Nanoparticles. Bioconjugate Chem. 2006, 17, 1373-1375.

(38) Gole, A.; Murphy, C. J. Azide-Derivatized Gold Nanorods: Functional Materials for Click Chemistry. Langmuir 2008, 24, 266 272.

(39) Zhu, K.; Zhang, Y.; He, S.; Chen, W.; Shen, J.; Wang, Z.; Jiang, X. Quantification of Proteins by Functionalized Gold Nanoparticles Using Click Chemistry. Anal. Chem. 2012, 84, 4267-4270.

(40) Pickens, C. J.; Johnson, S. N.; Pressnall, M. M.; Leon, M. A.; Berkland, C. J. Practical Considerations, Challenges, and Limitations of Bioconjugation via Azide - Alkyne Cycloaddition. Bioconjugate Chem. 2018, 29, 686-701.

(41) Roll, D.; Malicka, J.; Gryczynski, I.; Gryczynski, Z.; Lakowicz, J. R. Metallic Colloid Wavelength-Ratiometric Scattering Sensors. Anal. Chem. 2003, 75, 3440-3445.

(42) Oh, E.; Hong, M.-Y.; Lee, D.; Nam, S.-H.; Yoon, H. C.; Kim, H.-S. Inhibition Assay of Biomolecules based on Fluorescence Resonance Energy Transfer (FRET) between Quantum Dots and Gold Nanoparticles. J. Am. Chem. Soc. 2005, 127, 3270-3271.

(43) Nash, M. A.; Yager, P.; Hoffman, A. S.; Stayton, P. S. Mixed Stimuli-Responsive Magnetic and Gold Nanoparticle System for Rapid Purification, Enrichment, and Detection of Biomarkers. Bioconjugate Chem. 2010, 21, 2197-2204.

(44) Caswell, K. K.; Wilson, J. N.; Bunz, U. H. F.; Murphy, C. J. Preferential End-to-End Assembly of Gold Nanorods by BiotinStreptdavidin Connectors. J. Am. Chem. Soc. 2003, 125, 1391413915.

(45) Liao, H.; Hafner, J. H. Gold Nanorod Bioconjugates. Chem. Mater. 2005, 17, 4636-4641.

(46) Wang, Y.; Zijlstra, P. Plasmon-Enhanced Single-Molecule Enzymology. ACS Photonics 2018, 5, 3073-3081.

(47) Blanco-Canosa, J. B.; Wu, M.; Susumu, K.; Petryayeva, E.; Jennings, T. L.; Dawson, P. E.; Algar, W. R.; Medintz, I. L. Recent progress in the bioconjugation of quantum dots. Coord. Chem. Rev. 2014, 263-264, 101-137.

(48) FRENS, G. Controlled Nucleation for the Regulation of the Particle Size in Monodisperse Gold Suspensions. Nature, Phys. Sci. 1973, 241, 20.

(49) Bastús, N. G.; Merkoçi, F.; Piella, J.; Puntes, V. Synthesis of Highly Monodisperse Citrate-Stabilized Silver Nanoparticles of up to 200 nm: Kinetic Control and Catalytic Properties. Chem. Mater. 2014, 26, 2836-2846.

(50) Wan, J.; Wang, J.-H.; Liu, T.; Xie, Z.; Yu, X.-F.; Li, W. Surface chemistry but not aspect ratio mediates the biological toxicity of gold nanorods in vitro and in vivo. Sci. Rep. 2015, 5, 11398.

(51) Bastos, V.; de Oliveira, J. F.; Brown, D.; Jonhston, H.; Malheiro, E.; da Silva, A. D.; Duarte, I.; Santos, C.; Oliveira, H. The influence of Citrate or PEG coating on silver nanoparticle toxicity to a human keratinocyte cell line. Toxicol. Lett. 2016, 249, 29-41.

(52) Indrasekara, A. S. D. S.; Wadams, R. C.; Fabris, L. Ligand Exchange on Gold Nanorods: Going Back to the Future. Particle \& Particle Systems Characterization 2014, 31, 819-838.

(53) Kawakatsu, T. Statistical Physics of Polymers: An Introduction; Advanced Texts in Physics; Springer-Verlag: Berlin Heidelberg, 2004.

(54) Rahme, K.; Chen, L.; Hobbs, R. G.; Morris, M. A.; O’Driscoll, C.; Holmes, J. D. PEGylated gold nanoparticles: polymer quantification as a function of PEG lengths and nanoparticle dimensions. RSC Adv. 2013, 3, 6085-6094.

(55) Yorulmaz, M.; Khatua, S.; Zijlstra, P.; Gaiduk, A.; Orrit, M. Luminescence Quantum Yield of Single Gold Nanorods. Nano Lett. 2012, 12, 4385-4391.
(56) Vranish, J. N.; Ancona, M. G.; Walper, S. A.; Medintz, I. L. Pursuing the Promise of Enzymatic Enhancement with Nanoparticle Assemblies. Langmuir 2018, 34, 2901-2925.

(57) Katira, P.; Agarwal, A.; Hess, H. A Random Sequential Adsorption Model for Protein Adsorption to Surfaces Functionalized with Poly(ethylene oxide). Adv. Mater. 2009, 21, 1599-1604.

(58) Min, H.; Freeman, E.; Zhang, W.; Ashraf, C.; Allara, D.; van Duin, A. C. T.; Tadigadapa, S. Modified Random Sequential Adsorption Model for Understanding Kinetics of Proteins Adsorption at a Liquid-Solid Interface. Langmuir 2017, 33, 7215-7224.

(59) Melo, R. C. N.; Morgan, E.; Monahan-Earley, R.; Dvorak, A. M.; Weller, P. F. Pre-embedding immunogold labeling to optimize protein localization at subcellular compartments and membrane microdomains of leukocytes. Nat. Protoc. 2014, 9, 2382-2394.

(60) Blythe, K. L.; Willets, K. A. Super-Resolution Imaging of Fluorophore-Labeled DNA Bound to Gold Nanoparticles: A SingleMolecule, Single-Particle Approach. J. Phys. Chem. C 2016, 120, 803815

(61) Taylor, A.; Verhoef, R.; Beuwer, M.; Wang, Y.; Zijlstra, P. AllOptical Imaging of Gold Nanoparticle Geometry Using SuperResolution Microscopy. J. Phys. Chem. C 2018, 122, 2336-2342.

(62) Saha, B.; Saikia, J.; Das, G. Correlating enzyme density, conformation and activity on nanoparticle surfaces in highly functional bio-nanocomposites. Analyst 2015, 140, 532-542. 